\title{
Free Indirect Discourse and 'De Re' Pronouns
}

\author{
Yael Sharvit \\ University of Connecticut
}

\section{Background and Goal}

In English, John said that I feel sick today cannot mean that John uttered "I feel sick today." Recently, it has been observed (see Anand and Nevins 2004 and references cited there) that in some languages the corresponding sentence can mean precisely that. This suggests that at least in those languages attitude verbs such as say may quantify over contexts (and their embedded clause may be interpreted relative to a context, or contexts, different from the one relative to which the matrix clause is interpreted), in violation of Kaplan's (1979) famous prohibition. Schlenker $(1999,2003)$ has argued that attitude verbs in all languages quantify over contexts, but the lexical properties of $I$ and today, in languages such as English, prevent them from "shifting" their reference (this is why $I$ and today in the above example refer to the speaker and the day surrounding the utterance time respectively). I argue that the notion 'context', as usually used in the relevant literature, is not fine-grained enough to capture subtle contrasts between Standard Indirect Discourse (embedding of a clause under an attitude verb; henceforth, SID) and Free Indirect Discourse (henceforth, FID). FID involves quantification over contexts, where 'context' should be understood in its "broad" sense, namely, as including a variable assignment.

FID is a literary style that narrators use to convey the point of view of a character in a story (usually, but not always, a written story). (1) illustrates this.

John bid me goodbye, and walked home. He would ask me to marry him today(, he thought).

John to himself: "I will ask Yael to marry me today."

The material that appears in parentheses is optional; we can usually infer from the preceding text whose point of view is reported, and where or when the event of thinking or saying takes place. The paraphrase of the thought in (1) shows that he may be used to refer to whoever the attitude holder - in this case John - takes himself to be (the "embedded" author), the past tense (on would) - to the time where the attitude holder locates himself, $m e / I$ refers to the speaker (the "matrix" author) ${ }^{1}$ and today is used to refer to the day surrounding the time where the attitude holder locates himself.

In many ways FID resembles SID. In SID, too, he can be used to refer to the embedded author, the past tense - to the time where the attitude holder locates himself, and $m e / I$ is used to refer to the matrix author. However, in SID, unlike FID, today must refer to the day surrounding the time where the speaker locates herself, not the day surrounding the time where the attitude holder locates himself. Thus, (2a) is a good paraphrase of (1), but (2b) is not. 
a. John thought that he would ask me to marry him that day.

b. John thought that he would ask me to marry him today.

In short, today and $I$ are interpreted relative to the speaker in SID; but in FID $I$ is interpreted relative to the speaker, today is not (see Banfield 1982, Doron 1991). ${ }^{2}$

In this paper I observe additional contrasts between FID and SID, mainly regarding the behavior of pronouns. I argue that: (a) the English FID operator quantifies over "broad" contexts (and consequently over variable assignments); (b) as a result, pronouns in English FID usually do not receive their values from the assignment supplied by the utterance context; and (c) by contrast, attitude verbs in English do not quantify over "broad" contexts, and pronouns in complement clauses of such verbs may receive their values from the assignment supplied by the utterance context.

\section{An Analysis of FID Along the Lines of Doron (1991)}

Building on an idea in Banfield (1982), Doron (1991) proposes a theory of FID which roughly says the following. The embedded clause in FID is interpreted relative to two contexts: the utterance context (tied to the speaker), and an embedded context (tied to the attitude holder). In SID, by contrast, the embedded clause is interpreted relative to the utterance context. I think Doron's proposal is essentially correct. However, there are certain issues (e.g., the interpretation of free $3^{\text {rd }}$ person pronouns) about which Doron's paper is not explicit (or not explicit enough). In what follows I try to make explicit what I think should be part of any theory of FID, the part that explains the behavior of free pronouns.

Doron's proposal is couched within the framework of Situation Semantics. My own rendition of her proposal doesn't make any essential use of that particular theory. At the risk of doing an injustice to Doron's proposal, here is my rendition of it. All expressions are interpreted relative to two contexts (c and C; C being the utterance context), and a (possibly partial) variable assignment. In the default case, c=C. A context is understood in the "broad" sense, namely, as <author, (addressee,) world, time, location,..., assignment function>, where the range of the assignment function is a set of entities salient for the author of the context in the world/time/location of the context. The literature on attitude reports usually uses the notion "context' in its "narrow" sense. (By "narrow context" I mean: something that is like a broad context but lacks a variable assignment.)

The FID operator (which, I assume, is the "embedder" in FID constructions) is a universal quantifier over broad context-assignment pairs, and its complement clause denotes a function from such pairs to truth values. An attitude verb is a universal quantifier over narrow contexts (or perhaps over things that are even "smaller"), and its complement clause denotes a function from narrow contexts (or "smaller" things) to truth values. In addition to the usual rules we have the rules in (3) (of which (3c,d) are fairly standard), where $c$ and $\mathrm{C}$ are any broad contexts, and $\mathrm{g}$ is any assignment: 
(3) (a) For any root node $S$, $[S S]^{c, C, g}$ is defined only if $c=C, C$ is the utterance context, $g=a s s i g n m e n t(c)$, and $\operatorname{Dom}(g)$ is the set of indices that are syntactically free in $\mathrm{S}^{3}$

(b) $\llbracket\left[\prod^{\mathrm{c}, \mathrm{C}, \mathrm{g}}\right.$ is author(C); [today $\rrbracket^{\mathrm{c}, \mathrm{C}, \mathrm{g}}$ is the day surrounding time(c).

(c) For any index $\mathrm{j}$ and variable (trace or pronoun) $\alpha$, $\llbracket \alpha_{\mathrm{j}} \rrbracket^{\mathrm{c}, \mathrm{C}, \mathrm{g}}$ is defined only if $\mathrm{j} \in \operatorname{Dom}(\mathrm{g})$. When defined, $\llbracket \alpha_{\mathrm{j}} \rrbracket^{\mathrm{c}, \mathrm{C}, \mathrm{g}}=\mathrm{g}(\mathrm{j})$.

(d) For any branching node $\alpha$, if the daughters of $\alpha$ are $\beta$ and $\gamma$, and $\beta$ dominates only an index $\mathrm{j}, \llbracket \alpha]^{\mathrm{c}, \mathrm{C}, \mathrm{g}}=[\lambda \mathrm{x}: \gamma$ is in the domain of II $\mathbb{I}^{c, C, g[j \rightarrow x]}$. If $\left.y \mathbb{I}^{c, C, g[j \rightarrow x]}\right]$ (where $g[j \rightarrow x]$ is just like $g$ but for the possible exception that $g[j \rightarrow x](j)=x)$.

(e) For any index $\mathrm{j}, \llbracket w_{\mathrm{j}} \rrbracket^{\mathrm{c}, \mathrm{C}, \mathrm{g}}$ is defined only if: (i) $\mathrm{g}(\mathrm{j}) \in \mathrm{D}_{\mathrm{s}}$; and (ii) whenever $g$ and assignment(c) agree on $j, g(j)=$ world(c).

Here is how the observed contrast between $I$ and today is accounted for. Consider the SID in (4a) and the FID in (4b).

a. (John stared at me.) He thought that I would resign today.

b. (John stared at me.) I would resign today(, he thought).

Assuming that the LF of the embedded clause in (4a) is: [that 11 I will resign- $w_{1}$ today] (where $w_{1}$ is the pronominal world argument of will resign and 1 - its syntactic binder), (4a) is interpreted as in (5), relative to c, C, and g. For simplicity, we ignore some of the context parameters that think quantifies over. (In section 4 we discuss how the embedded past "disappears".)

(5) For all worlds w compatible with what John believes in world(c) at some time before time $(\mathrm{c})(\mathrm{c}=\mathrm{C})$, $\llbracket I$ will resign- $w_{1}$ today $\prod^{\mathrm{c}, \mathrm{C}, \mathrm{g}[1 \rightarrow \mathrm{w}]}=1$ (i.e., author(C) (=the speaker) will resign in $w$ at the day surrounding time $(C)$ ).

The pronoun $w_{1}$ is syntactically bound, so by $(3 \mathrm{c}, \mathrm{d})$ it denotes $\mathrm{w}$ for every relevant world $\mathrm{w}$. By (3b), I denotes author(C); today denotes the day surrounding time(c). By (3a) c=C, so time (c)=time $(C)$. The LF of the embedded clause in (4b) is: [I will resign- $w_{1}$ today], and (4b) is interpreted as in (6), relative to c, C, and $\mathrm{g}$.

For all broad context-assignment pairs <', g' $>$ such that c' is compatible with what John believes in world(c) at some time before time(c) $(c=C)$ and g'=assignment(c'), [I will resign- $w_{1}$ today $\mathbb{I}^{\prime}, \mathrm{C}, \mathrm{g}^{\prime}=1$ (i.e., author(C) (=the speaker) will resign at the day surrounding time(c') in world(c')).

This time, $w_{1}$ has no syntactic binder but it is semantically bound: by $(3 \mathrm{c}, \mathrm{e})$ it denotes world(c'), for every relevant c' (assignment $\left(c^{\prime}\right)=g^{\prime}$, so they agree on 1 ; this means that g'(1) is a world compatible with what John believes in the actual world). By (3b), I denotes author(C), and today denotes, for every relevant c', the day surrounding time $\left(c^{\prime}\right)\left(c^{\prime} \neq C\right.$, so it is the day surrounding the time where John, not the speaker, locates himself). 
The proposal also makes a nice prediction regarding definite descriptions. It is well known that in SID definite descriptions may have a 'wide scope' reading or a 'narrow scope' reading. But this is not so in FID (Doron 1991, Banfield 1982, Schlenker 1999, 2004), where only a 'narrow scope' reading is available. For example, in the SID in (7), the dean may be the actual dean or the dean according to Mary, but in the FID in (8), the dean is the dean according to Mary.

(7) Mary believed that the dean was shy in his childhood.

(8) The dean was shy in his childhood(, thought Mary).

(9) spells out the two interpretations of (7). In the 'narrow' interpretation, the pronominal world argument of dean is syntactically bound. In the 'wide' interpretation, it is syntactically free, and by $(3 \mathrm{c}, \mathrm{e})$, it denotes world(c) $(\mathrm{g}[1 \rightarrow \mathrm{w}]$ and assignment(c) agree on 2 , because assignment $(c)=g$ ). Since $c=C$, the world argument of dean denotes world(C) (the actual world).

a. 'Narrow scope' LF of embedded clause: [1 the dean-w $w_{1}$ was shy-w $w_{1}$ ] For all w compatible with what Mary believed in world(C), 【the dean$w_{1}$ was shy- $w_{1} \mathbb{I}^{\mathrm{c}, \mathrm{C}, \mathrm{g}[1 \rightarrow \mathrm{w}]}=1$ (the dean in $\mathrm{w}$ was shy in $\mathrm{w}$ ).

b. 'Wide scope' LF of embedded clause: [1 the dean-w2 was shy- $w_{1}$ ] For all w compatible with what Mary believed in world(C), [the dean$w_{2}$ was shy-w $\mathbb{I}^{\mathrm{c}, \mathrm{C}, \mathrm{g}[1 \rightarrow \mathrm{w}]}=1$ (the dean in world(C) was shy in $\mathrm{w}$ ).

(10) spells out the interpretation of (8). The world argument of dean is syntactically free (though semantically bound), so it doesn't matter how we index it: by $(3 c, e)$ it denotes world(c') no matter what its index is.

(10) LF of embedded clause: [the dean- $w_{1 / 2}$ was shy-w $\left.w_{1}\right]$

For all $\left\langle c^{\prime}, g^{\prime}\right\rangle$ such that $c^{\prime}$ is compatible with what Mary believed in

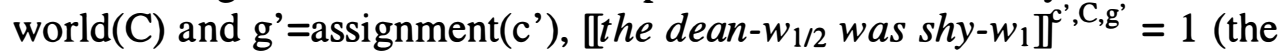
dean in world(c') was shy in world(c')).

Why can't the free pronominal world argument of dean be interpreted as world(C) in (10)? According to the theory sketched here, this is because it has no access to the assignment supplied by the "matrix" (i.e., utterance) context. I argue that this is characteristic of pronouns in FID: in the default case, their values are not fixed by the matrix assignment, and they cannot be interpreted 'de re'.

\section{More FID/SID Contrasts: 'De Re' Readings of Pronominal Expressions}

I use the term 'de re' pronoun to talk about a syntactically free pronoun in an "attitude" environment that reflects the speaker's point of view (e.g., $w_{2}$ in (9b)). A "null" pronoun is a pronoun that is interpreted as a world/time where the attitude holder locates himself (e.g., $w_{1}$ in (5) and (6); the past tense in (1)), or an individual he takes himself to be (e.g., he in (1)). "Null" pronouns can be 
syntactically bound (e.g., $w_{1}$ in (5)) or free (e.g., $w_{1}$ in (6)). I use the term 'de dicto' pronoun to talk about a syntactically free pronoun that is not "null", but still reflects the attitude holder's point of view (examples are given below). In this section I show that pronouns in FID are usually not 'de re' pronouns. At a first glance, this claim seems false.

\subsection{Apparent 'de re' readings of $3^{\text {rd }}$ person pronouns in FID}

If we construct an example of FID with a syntactically free $3^{\text {rd }}$ person pronoun, we get the impression that it is possible to treat it as a 'de re' pronoun.

(11) John looked at Bill. He wanted to tell him something now, he could feel it. John: "This guy wants to tell me something now, I can feel it."

The second sentence in (11) is FID. Since John is reported to have a thought about Bill, it makes sense to interpret he as referring to Bill. This seems to indicate that $h e$ is a 'de re' pronoun in (11). Furthermore, a free $3^{\text {rd }}$ person pronoun in FID seems to behave in the same way as it does in SID in scenarios involving identification errors. To see this, let us first look at the SID in (12) (constructed after Quine's 1956 famous example), which has a reading that doesn't imply that John has contradictory beliefs. This reading comes about when John sees Mary on two different occasions and fails to recognize that he sees the same person. Based on the first encounter he attributes to Mary the property of being a spy, and based on the second encounter he attributes to her the property of not being a spy.

(12) John believes that Mary is a spy, and at the same time, he believes that Mary is not a spy.

If we replace Mary with a pronoun that refers to Mary, we get the same effect.

John believes that she is a spy, and at the same time, that she is not a spy.

FID is different. A contradictory-beliefs reading arises with a name; but a reading that doesn't imply contradictory beliefs is possible with a pronoun.

(14) \#Mary was a spy(, thought John listening to a recording of Mary's voice). Mary wasn't a spy(, thought John, listening at the same time to a different recording of Mary's voice).

She was a spy(, thought John, listening to a recording of Mary's voice). She wasn't a spy(, thought John, listening at the same time to a different recording of Mary's voice).

The oddity of (14) suggests that it attributes to John contradictory beliefs. This in turn suggests that names in FID, like definite descriptions (see (8)), are interpreted as having 'narrow' scope. (15), however, does not imply that John entertains contradictory beliefs. Therefore, (15) seems to indicate that she may receive a 'de re' interpretation in FID. Nevertheless, I claim that this pronoun is not a 'de re' 
pronoun (but rather a 'de dicto' pronoun). I now introduce data that show that $3^{\text {rd }}$ person pronouns and the present tense cannot be 'de re' pronouns in FID.

\subsection{Gender identification errors}

In scenarios where an individual forms a belief about someone regarding whose gender he is mistaken, we observe a contrast between FID and SID, when we report that. Suppose John sees Bill (a male individual) in a dress, and mistakes him for a female individual. John mutters: "Really, she looks great, and she is staring at me." If we report this using FID, there is a preference for using she, and not he, to refer to Bill (even though for us, Bill is a male). ${ }^{4}$

(16) John was convinced that Bill was a woman. Really, she/\#he looked great(, he muttered), and she/\#he was staring at him.

This is explained if $3^{\text {rd }}$ person pronouns in FID are not 'de re' pronouns. If it were possible to treat he as a 'de re' pronoun here we would have no preference for using she, since we, unlike John, take Bill to be a male. She is a 'de dicto' pronoun here, reflecting John's point of view rather than the speaker's. Even if we don't tell our audience about John's mistake, they will still be able to reconstruct what he said (and infer his mistake). But if we report what happened using SID, we have to use he (which in this case is a 'de re' pronoun, reflecting the speaker's point of view).

(17) John didn't realize that Bill was a man. He said that he/\#she looked great and that he/\#she was staring at him.

One way to rescue she in (17) is to treat it as an E-type pronoun, but this is possible only if there is an overt antecedent preceding she, as in (18), where the antecedent is a woman and she is shorthand for the woman he thought he saw.

John looked at Bill and thought he saw a woman. He said that he/she looked great, and that he/she was staring at him.

How do we know that she is not an E-type pronoun in (16)? Without an overt antecedent, she would still be acceptable, as shown in (19).

John didn't realize that Bill was a man. Really, she/\#he looked great(, he muttered), and she/\#he was staring at him.

\subsection{The unavailability of 'double access' readings in FID}

It is well known that in English SID, a present tense embedded under a past tense refers to a time that overlaps the utterance time. This is illustrated in (20). Such readings are called 'double access' readings, because of the inference in (20b), which requires at least two times to be included in the time of the pregnancy. 
Three days ago, John found out that Mary is pregnant.

$==>$ a. John to himself: "Mary is pregnant (now)"

$==>$ b. Mary's pregnancy stretches (at least) from three days ago to the utterance time.

In this respect, the present tense differs dramatically from the past tense in English. This is illustrated by the contrast between (21) and (22).

Two years ago, John found out that Mary was pregnant. $==>$ John to himself: "Mary is pregnant (now)"

\#Two years ago, John found out that Mary is pregnant.

(21) is fine because English, being a Sequence-of-Tense (SOT) language, allows a tense embedded under an agreeing tense to be a "null" time-denoting pronoun (i.e., a relative "now") rather than an "anteriority" time-denoting pronoun. Since find out is factive and the finding out is in the past, the actual pregnancy takes place in the past. (22) is odd because the time denoted by the present tense (the pregnancy time) is required to stretch from two years ago into the utterance time. This contradicts common knowledge regarding normal (human) pregnancies.

This explanation of the facts is possible under the assumption (Abusch 1997, Heim 1994 among others) that the English present tense in SID is a 'de re' pronoun whose presuppositions require it to denote a time overlapping the utterance time. ${ }^{5}$ Now, if we look at tenses in English FID, we notice that: (a) present-under-past is marginal at best; ${ }^{6}$ (b) past-under-past and present-underpresent (where the embedding present may be a "historical" present) are acceptable; and (c) in any event, an embedded present need not denote a time that overlaps the time in which the story is told (the utterance time).

(23) a. \#She is pale today, said Mary as she stared into the horizon.

b. She was pale today(, said Mary as she stared into the horizon).

c. She is pale today(, says Mary, staring into the horizon).

Mary: "I am pale today."

(23b) is good because the embedded past is "null" (a SOT effect, cf. (21)). Neither (23c) nor the marginal (23a) (provided we accept it) imply that the time of Mary's paleness (or whatever it is that leads her to say she is pale) extends into the time where the story is told. This is explained if the present in FID cannot be interpreted 'de re'. The marginality of (23a) suggests that there is a preference for a "null" present in FID, and that (23c) is good because of that: morphologically, the matrix tense (silent or not) is present, and it agrees with the embedded tense.

\subsection{Condition $B / C$ effects}

Condition B of the Binding Theory usually prevents co-arguments of a verb from having the same reference (unless one of them is a reflexive pronoun). This is 
why usually, She/Mary likes her cannot mean that Mary likes Mary. This effect is preserved in complement clauses of attitude verbs, as shown below. Consider the following scenario. John is looking at Mary. He doesn't recognize her; in fact he has no idea who he is looking at. He mutters: "Mary doesn't know her. I'm sure of this." If we report what happened to someone else, there is a contrast between the resulting FID and SID reports.

(24) John looked at Mary. He didn't recognize her. \#He muttered to himself that Mary/she didn't know her and that he was sure of that.

John looked at Mary. He didn't recognize her. Mary/she didn't know her; he was sure of this(, he muttered to himself).

(24) is not a good way to report what John said, because the embedded she and her are 'de re' pronouns, and reflect our point of view (as does Mary). Since we know that John is looking at Mary, a Condition B violation arises. (25) is good because neither she nor her are 'de re' pronouns. Rather, they are 'de dicto' pronouns, and reflect John's point of view (as does Mary). As such they may refer to different individuals. Even if the audience of (25) is not aware of John's mistake, they will still be able to reconstruct what he said (and infer his mistake). This doesn't seem to be possible in (24). Notice that (24) can be rescued using the E-type strategy, but this requires an overt antecedent for she/her (cf. (18)).

(26)-(27) make a similar point regarding Condition $C$ (which often prevents a pronoun from being coreferential with a name it c-commands).

(26) John looked at Mary. He didn't recognize her. \#He thought that she didn't know Mary.

(27) John looked at Mary. He didn't recognize her. She didn't know Mary(, he thought).

\subsection{The antecedent options of $\mathrm{it} / \mathrm{that}$}

It is well known that it and that may refer back to a proposition, as shown in (28).

John believes that Mary is a spy. But it/that isn't true. Mary is not a spy.

The proposition that serves as the antecedent of it/that is 'that Mary is a spy'. For convenience, let us represent this proposition as the ordered pair $<$ Mary, SPY $>$.

For many (though admittedly not all) speakers, there is a contrast between FID and SID in terms of the kind of propositions that may serve as antecedents for it/that (cf. Sharvit 2003). This is best illustrated in a scenario where an individual sees a reflection of himself but thinks that he is looking at someone else, as reported in (29) and (30). The second sentence in (29) is SID.

(29) John looked in the mirror, and failed to realize that what he was looking at was his own reflection. He thought that he was sick. It/that wasn't true. John was perfectly fine.

$$
\text { (【it/that } \rrbracket=<\llbracket \text { he } \rrbracket(=\mathrm{John}), \mathrm{SICK}>)
$$


This text is unproblematic. It/that refers to the proposition <John, SICK > which is formed by taking the referent of he and the SICK property. Since he is a 'de re' pronoun, the referent of he is John. It/that wasn't true denies the truth of <John, SICK $>$. When we switch to FID, we get a different result:

(30) John looked in the mirror, and failed to realize that what he was looking at was his own reflection. He was sick(, thought John). It/that wasn't true. \#John was perfectly fine.

$(\llbracket i t /$ that $\rrbracket=<\llbracket h e \rrbracket(\neq \mathrm{John}), \mathrm{SICK}>)$

The result is odd because we are negating the proposition formed of the referent of he and SICK. But the referent of he is not John now. This is because he is not interpreted 'de re' (but rather 'de dicto', from John's point of view).

To sum up, pronouns can be interpreted 'de re' in SID, but not in FID. This is explained by our rendition of Doron's proposal. 'De re' pronouns are free pronouns that receive their values from the matrix assignment. Quantifying over broad contexts in FID means that syntactically free pronouns "trapped" in FID do not receive their values from the matrix assignment. Some of them are "null", and those that are not are 'de dicto' pronouns.

\section{The proposal}

\subsection{General assumptions}

In addition to the rules in (3), we need a system that accounts for "null" pronouns. For example (see (1)), we need to account for the fact that a past embedded under another past in English may refer to a time where the attitude holder locates himself (simultaneous 'de nunc' interpretation, to borrow von Stechow's (2003) term), and that a $3^{\text {rd }}$ person pronoun may refer to whoever the attitude holder takes himself to be ('de se' interpretation). To this end, I assume a feature deletion mechanism (in the style of Schlenker 1999, Heim 2001, and von Stechow 2003; cf. Kratzer 1998). More concretely, I assume that in unembedded environments past and he carry two indices (the subscripts in (31)-(32)), and features (the superscripts in (31)-(32)) that provide presuppositions applicable to the indices (' $<$ ' stands for the +PAST feature, and ' $3 \mathrm{M}$ ' stands for $3^{\text {rd }}$ person masculine).

(31) For any indices $\mathrm{k}, \mathrm{j}$, [past $t_{\mathrm{k}, \mathrm{j}} \mathrm{I}^{\mathrm{c}, \mathrm{C}, \mathrm{g}}$ is defined only if:

a. $\mathrm{g}(\mathrm{k})$ and $\mathrm{g}(\mathrm{j}) \in \mathrm{D}_{\mathrm{i}}$,

b. $g(j)$ precedes $g(k)$, and

c. whenever $\mathrm{g}$ and assignment(c) agree on $\mathrm{k}, \mathrm{g}(\mathrm{k})=$ time(c).

When defined, $\llbracket$ past $_{\mathrm{k}, \mathrm{j}}{ }^{<} \mathbb{F}^{\mathrm{c}, \mathrm{C}, \mathrm{g}}=\mathrm{g}(\mathrm{j})$.

(32) For any indices $\mathrm{k}, \mathrm{j}$, [he $e_{\mathrm{k}, \mathrm{j}}{ }^{\mathrm{M}} \mathbb{I}^{\mathrm{c}, \mathrm{C}, \mathrm{g}}$ is defined only if:

a. $g(k)$ and $g(j) \in D_{e}$,

b. $g(j)$ is a male in c, and

c. whenever $\mathrm{g}$ and assignment(c) agree on $\mathrm{k}, \mathrm{g}(\mathrm{k})=$ author(c). 
When defined, [he $e_{\mathrm{k}, \mathrm{j}}{ }^{3 \mathrm{M}} \mathrm{II}^{\mathrm{c}, \mathrm{C}, \mathrm{g}}=\mathrm{g}(\mathrm{j})$.

In SOT languages such as English, when past is c-commanded by an agreeing tense, and in Sequence-of-Person languages such as English, when he is ccommanded by an agreeing phrase, they may "lose" the second index (and with it, the relevant superscripts/presuppositions), as long as the first index is bound (syntactically or semantically). ${ }^{7,8}$ Then, they are interpreted as follows:

(33) For any $\mathrm{k}$, «past ${ }_{\mathrm{k}}{ }^{\mathrm{C}} \mathbb{I}^{\mathrm{c}, \mathrm{C}, \mathrm{g}}$ is defined only if: $\mathrm{g}(\mathrm{k}) \in \mathrm{D}_{\mathrm{i}}$ and whenever $\mathrm{g}$ and assignment(c) agree on $\mathrm{k}, \mathrm{g}(\mathrm{k})=$ time(c). When defined, $\left[\right.$ past $_{\mathrm{k}}{ }^{4} \prod^{\mathrm{c}, \mathrm{C}, \mathrm{g}}=\mathrm{g}(\mathrm{k})$.

(34) For any $\mathrm{k}$, The ${ }_{\mathrm{k}}{ }^{3 \mathrm{~A}} \mathrm{If}^{\mathrm{c}, \mathrm{C}, \mathrm{g}}$ is defined only if: $\mathrm{g}(\mathrm{k}) \in \mathrm{D}_{\mathrm{e}}$ and whenever $\mathrm{g}$ and assignment(c) agree on $\mathrm{k}, \mathrm{g}(\mathrm{k})=$ author(c). When defined, [he $e_{\mathrm{k}}^{3 \mathrm{AA}} \mathrm{If}^{\mathrm{c}, \mathrm{C}, \mathrm{g}}=\mathrm{g}(\mathrm{k})$.

Our assumptions about SID are not very different from von Stechow's (among others). Still, we go over some examples in detail so that the reader can appreciate the predictions concerning FID. We predict SID to support 'de re' pronouns, FID to support 'de dicto' pronouns, and both FID and SID to support "null" pronouns.

\section{2. $S I D$}

(35) is a well-known example, which illustrates a 'de re'/'de se' ambiguity exhibited by $3^{\text {rd }}$ person pronouns embedded under attitude verbs.

(35) Kaplan believed that his pants were on fire.

a. Kaplan to himself: "this guy's pants are on fire" ('de re')

b. Kaplan to himself: "my pants are on fire" ('de se'/"null")

(36) and (37) provide the LFs of (35a) and (35b) respectively (where the verbs take time arguments in addition to world arguments). We assume that believe is a universal quantifier over world-time-individual triples, and its clausal complement denotes a function from such triples to truth values. We also assume that the abstraction indices needed for that are freely supplied by the syntax ( 4 is an individual-abstractor, 2 - a time-abstractor, and 1 - a world-abstractor):

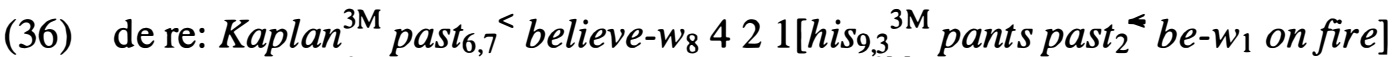

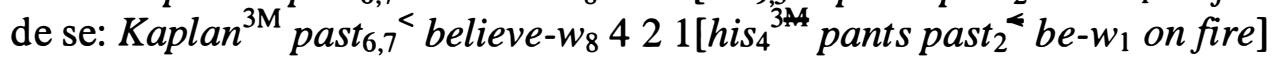

In (37) he is syntactically bound, and the past tense is syntactically bound in (36) and (37). The relevant features are deleted. This is allowed by our deletion mechanism, as past agrees with past and he/his agrees with Kaplan (both being $3 \mathrm{M})$. In (36) he/his is free and retains its features. We thus obtain (38) and (39).

'De re' interpretation (corresponding to (36)):

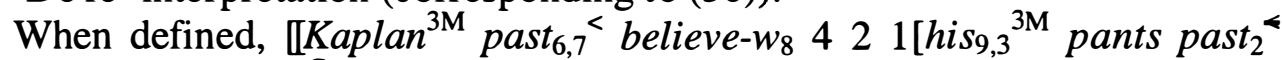
$b e-w_{1}$ on fire $] \mathbb{I}^{\mathrm{c}, \mathrm{C}, \mathrm{g}}=1$ iff for all individual-time-world triples $\left.<\mathrm{x}, \mathrm{t}, \mathrm{w}\right\rangle$ 
compatible with what Kaplan believes in world(C) at $\left[\right.$ past $_{6,7}{ }^{<\mathcal{C}, \mathrm{C}, \mathrm{g}}$, [his ${ }_{9,3}^{3 \mathrm{M}}$ pants past ${ }_{2}^{4}$ be- $w_{1}$ on fire $\prod^{\mathrm{C}, \mathrm{C}, \mathrm{g}[4 \rightarrow \mathrm{x}, 2 \rightarrow \mathrm{t}, 1 \rightarrow \mathrm{w}]}=1$.

Iff for all $<\mathrm{x}, \mathrm{t}, \mathrm{w}>$ compatible with what Kaplan believes in world(C) at [past ${ }_{6,7}^{<} \mathbb{I}^{\mathrm{C}, \mathrm{C}, \mathrm{g}}$, the pants of $\mathrm{g}(3)$ are on fire in $\mathrm{w}$ at $\mathrm{t}$.

'De se' interpretation (corresponding to (37)):

When defined, [IKaplan ${ }^{3 \mathrm{M}}$ past $_{6,7}<$ believe- $_{8} 421\left[\right.$ his $_{4}{ }^{34}$ pants past $_{2}{ }^{4}$ be$w_{1}$ on fire $\left.]\right]^{\mathrm{c}, \mathrm{C}, \mathrm{g}}=1$ iff for all individual-time-world triples $<\mathrm{x}, \mathrm{t}, \mathrm{w}>$ compatible with what Kaplan believes in world(C) at $\left[\right.$ past $_{6,7}{ }^{<} \mathbb{F}^{\text {,C,g }}$, [his ${ }_{4}{ }^{3 A 4}$ pants past ${ }_{2}{ }^{4}$ be- $w_{1}$ on fire $\mathbb{I}^{\mathrm{c}, \mathrm{C}, \mathrm{g}[4 \rightarrow \mathrm{x}, 2 \rightarrow \mathrm{t}, 1 \rightarrow \mathrm{w}]}=1$.

Iff for all $<\mathrm{x}, \mathrm{t}, \mathrm{w}>$ compatible with what Kaplan believes in world(C) at [past $\left.{ }_{6,7}<\right]^{\mathrm{c}, \mathrm{C}, \mathrm{g}}$, the pants of $\mathrm{x}$ are on fire in $\mathrm{w}$ at $\mathrm{t}$.

The interpretation of he/his in (36) depends on $\mathrm{g}[4 \rightarrow \mathrm{x}, 2 \rightarrow \mathrm{t}, 1 \rightarrow \mathrm{w}]$ (by (32)), which agrees with assignment(c) on the value assigned to 3 (by (3a), $\mathrm{g}=$ assignment(c)). Since $\mathrm{c}=\mathrm{C}$ (by (3a)), we get a 'de re' pronoun. In (37), he/his is bound and it is interpreted as whoever Kaplan takes himself to be (by the semantics of believe). Since past is bound, it is interpreted as Kaplan's "now".

It is important to bear in mind that (38) is a mere simplification of the "correct" 'de re' analysis, according to which he is a semantic argument of believe (see Cresswell and von Stechow 1982, among others). Kaplan may fail to identify the referent of he properly (cf. (12), (13)). This requires that the description that Kaplan uses for the referent of he be the same as the description that actually fits that referent, though it may pick out different individuals in the actual world and in the worlds compatible with Kaplan's beliefs. ${ }^{9}$

"Correct" 'de re' interpretation:

There is a suitable individual-concept $k$ (e.g., $\left[\lambda \mathrm{x} \in \mathrm{D}_{\mathrm{e}} \cdot \lambda \mathrm{t} \in \mathrm{D}_{\mathrm{i}} \cdot \lambda \mathrm{w} \in \mathrm{D}_{\mathrm{s}}\right.$. the unique $y$ such that $x$ sees $y$ in $w$ at $t]$ ) such that $k($ Kaplan $)\left(\llbracket\right.$ past $\left._{6,7}{ }^{<} \rrbracket^{\mathrm{C}, \mathrm{C}, \mathrm{g}}\right)($ world $(\mathrm{C}))=\mathrm{g}(3)$, and for all $<\mathrm{x}, \mathrm{t}, \mathrm{w}>$ compatible with what Kaplan believes in world(C) at $\left[\right.$ past $_{6,7} \mathbb{I f}^{\mathrm{c}, \mathrm{C}, \mathrm{g}}$, the pants of $k(\mathrm{x})(\mathrm{t})(\mathrm{w})$ are on fire in $\mathrm{w}$ at $\mathrm{t}$.

\section{3. $F I D$}

Following a suggestion in Schlenker 1999, I assume that the (silent) FID operator (much like believe), takes an individual (the protagonist of the story - the attitude holder), a world (in which the story takes place), and a time (in which the story takes place) as arguments, and then a fourth argument, a "clausal" one. I assume that feature deletion under agreement works here too: a c-commanding past tense may trigger "deletion" of an embedded past, ${ }^{10}$ and a c-commanding $3^{\text {rd }}$ person masculine noun phrase may trigger "deletion" of a $3^{\text {rd }}$ person masculine pronoun. For example, the FID he liked Mary(, thought John) may be represented as in (41). We will see below that the undeleted indices are semantically bound as required by the deletion mechanism. ( $\mathrm{SW}$ is the world in which the story takes place which, for convenience, we take to be the actual world.) 


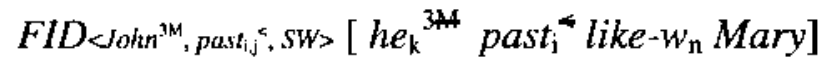

As a first attempt, let us take (42) to be the semantics of the FID operator.

(42) For any individual $x$, time $t$, world $w$, and function $f$ from broad contextassignment pairs to truth values, $\llbracket F I D \rrbracket^{\mathrm{c}, \mathrm{C}, \mathrm{g}}(\mathrm{x})(\mathrm{t})(\mathrm{w})(\mathrm{f})=1$ iff for all context-assignment pairs $\left\langle c^{\prime}, g^{\prime}\right\rangle$ such that $c^{\prime}$ is compatible with what $x$ believes/says in $\mathrm{w}$ at $\mathrm{t}$ and $\mathrm{g}^{\prime}=\operatorname{assignment}\left(\mathrm{c}^{\prime}\right), \mathrm{f}\left(\mathrm{c}^{\prime}\right)\left(\mathrm{g}^{\prime}\right)=1$.

Notice that there is a type mismatch between what the clausal complement of FID denotes according to (41) (i.e., something of type 't') and what FID requires it to denote according to (42). The rule in (43) resolves this mismatch, and also enables feature "deletion" (as the undeleted indices become semantically bound).

(43) MFA ("Monstrous" Functional Application; cf. Heim and Kratzer 1998)

If $\alpha$ is a branching node whose daughters are $\beta, \gamma$ and [ $\lambda c^{\prime} . \lambda g^{\prime}$. If $\left.\gamma \mathbb{I}^{c^{\prime}, C^{\prime}, g^{\prime}}\right]$

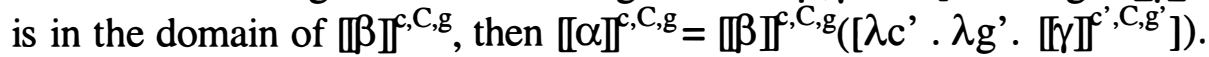

Now let us look at (44), which is ambiguous in a way similar to (35).

(44) He looked tired today(, thought John).

a. John to himself: "I look tired today." ('de se')

b. John to himself: "this guy looks tired today." ('de dicto')

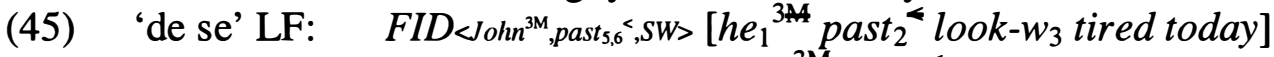

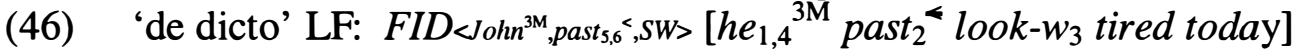

(47) 'De se' interpretation (corresponding to (45)):

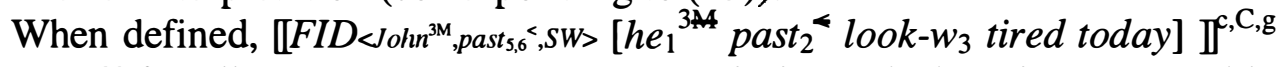
$=1$ iff for all context-assignment pairs <c',g'> such that c' is compatible

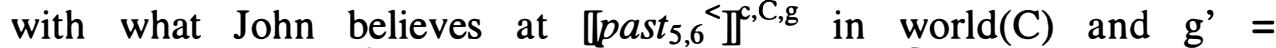
assignment(c'), [The ${ }_{1}^{3 \mathrm{~A}}$ past $_{2}{ }^{<}$look- $w_{3}$ tired today $\mathbb{I}^{\mathfrak{c}^{\prime}, \mathrm{C}, \mathrm{g}^{\prime}}=1$.

Iff for all $\left\langle c^{\prime}, g^{\prime}>\right.$ such that $c^{\prime}$ is compatible with what John believes at [past ${ }_{5,6}{ }^{<} \mathbb{F}^{\mathrm{C}, \mathrm{C}, \mathrm{g}}$ in world(C) and $\mathrm{g}^{\prime}=$ assignment(c'), author(c') looks tired in world(c') at time(c') at the day surrounding time(c').

(48) 'De dicto' interpretation (corresponding to (46)):

When defined, [FID $<$ John $^{3 \mathrm{M}}$, past $_{5,6}, S W>\left[\right.$ he $_{1,4}{ }^{3 \mathrm{M}}$ past $_{2}{ }^{<}$look- w $_{3}$ tired today $] \mathbb{I}^{\mathrm{c}, \mathrm{C}, \mathrm{g}}$ $=1$ iff for all context-assignment pairs <c',g'> such that c' is compatible with what John believes at $\llbracket$ past $_{5,6}{ }^{<} \prod^{\mathrm{C}, \mathrm{C}, \mathrm{g}}$ in world(C) and g'=assignment(c'), [he $e_{1,4}{ }^{3 \mathrm{M}}$ past $_{2}{ }^{*}$ look- $w_{3}$ tired today $\mathbb{I}^{\mathcal{C}^{\prime}, \mathrm{C}^{\prime}, \mathrm{g}^{\prime}}=1$.

Iff for all $\left\langle\mathrm{c}^{\prime}, \mathrm{g}\right\rangle$ such that $\mathrm{c}^{\prime}$ is compatible with what John believes at [past ${ }_{5,6}{ }^{<} \mathbb{F}^{,}, \mathrm{C}, \mathrm{g}$ in world(C) and g'=assignment(c'), g'(4) looks tired in world(c') at time(c') at the day surrounding time(c').

In (45) he has a free index and a deleted feature; its value is fixed by assignment(c') (see (34)) as author(c'). In (46) he has two free indices and no deleted features; its value is fixed by assignment(c') (see (32)) as some male in c'. 
But according to (48), there is no connection at all between the value assigned by assignment(c') to he and the value assigned to it by assignment $(\mathrm{C})$. Technically, we should establish such a connection (since John is acquainted with the referent of he). We want the description that John uses for the referent of he to be the description that actually fits that referent (as we do in 'de re' belief reports, see (40)), though this description may pick out different individuals in the actual context and in the contexts compatible with John's beliefs. Therefore, we have to enrich the semantics of $F I D$ with a presupposition that guarantees this (see (49)(50)). We thus obtain (51) as the relevant presuppositions of (46).

Revised semantics for the FID operator:

For any individual $x$, time $t$, world $w$ and function $f$ such that $f$ is a function from broad context-assignment pairs to truth values, $\llbracket F I D \prod^{\mathfrak{c}, C, g}(x)(t)(w)(f)$ is defined only if all context-assignment pairs $<c^{\prime}, g^{\prime}>$ such that c' is compatible with what $x$ believes/says in $w$ at $t$ and $\mathrm{g}^{\prime}=$ assignment $\left(\mathrm{c}^{\prime}\right)$, are compatible with $\mathrm{C}$ relative to $\left.<\mathrm{x}, \mathrm{t}, \mathrm{w}\right\rangle$.

When defined, $\llbracket F I D]^{\mathrm{c}, \mathrm{C}, \mathrm{g}}(\mathrm{x})(\mathrm{t})(\mathrm{w})(\mathrm{f})=1$ iff for all context-assignment pairs $\left\langle c^{\prime}, g^{\prime}>\right.$ such that $c^{\prime}$ is compatible with what $x$ believes in $w$ at $t$ and $\mathrm{g}^{\prime}=\operatorname{assignment}\left(\mathrm{c}^{\prime}\right), \mathrm{f}\left(\mathrm{c}^{\prime}\right)\left(\mathrm{g}^{\prime}\right)=1$.

(50) $c^{\prime}$ is compatible with $C$ relative to $\langle x, t, w\rangle$ iff: for every $j$ in Dom(assignment(c')) there is a suitable concept $\mathrm{k}_{\mathrm{j}}$, such that:

(i) $\quad$ assignment $(C)(j)=k_{j}(<x, t, w>)$;

(ii) $\quad \operatorname{assignment}\left(\mathrm{c}^{\prime}\right)(\mathrm{j})=\mathrm{k}_{\mathrm{j}}\left(<\operatorname{author}\left(\mathrm{c}^{\prime}\right)\right.$, time $\left(\mathrm{c}^{\prime}\right)$, world $\left.\left(\mathrm{c}^{\prime}\right)>\right) ;{ }^{11}$ and

(iii) whenever assignment $\left(c^{\prime}\right)(j)=\operatorname{author}\left(c^{\prime}\right)$, assignment $(C)(j)=x$.

(51) For all <c',g'> such that c' is compatible with what John believes at [past $5,6{ }^{<} \mathbb{I}^{\mathrm{c}, \mathrm{C}, \mathrm{g}}$ in world(C) and $\mathrm{g}^{\prime}=$ assignment $\left(\mathrm{c}^{\prime}\right)$ :

(a) $\mathrm{g}^{\prime}(1)=k_{1}\left(\right.$ author $\left.\left(\mathrm{c}^{\prime}\right)\right)\left(\operatorname{time}\left(\mathrm{c}^{\prime}\right)\right)\left(\right.$ world $\left.\left(\mathrm{c}^{\prime}\right)\right)=$ author $\left(\mathrm{c}^{\prime}\right)$;

(b) $\mathrm{g}(1)=k_{1}(\mathrm{John})\left(\llbracket\right.$ past $\left._{5,6}{ }^{<} \mathbb{I}^{\mathrm{c}, \mathrm{C}, \mathrm{g}}\right)($ world(C)) $=\mathrm{John}$;

(c) $\mathrm{g}^{\prime}(4)=k_{4}\left(\right.$ author $\left.\left(\mathrm{c}^{\prime}\right)\right)\left(\right.$ time $\left.\left(\mathrm{c}^{\prime}\right)\right)\left(\right.$ world $\left.\left(\mathrm{c}^{\prime}\right)\right)$; and

(d) $\mathrm{g}(4)=k_{4}(\mathrm{John})\left(\left[\right.\right.$ past $\left._{5,6}{ }^{<} \prod^{\mathrm{c}, \mathrm{C}, \mathrm{g}}\right)($ world(C) $)$.

Accordingly, under the 'de dicto' reading, John may "disagree" with the speaker regarding the identity of the individual with whom he is acquainted.

In sum, our system predicts that a 'de dicto' pronoun is possible in FID, but not in SID, where free pronouns in the embedded clause are 'de re' pronouns. Both SID and FID admit 'de se'/'de nunc' pronouns (which are bound syntactically and/or semantically). The reader may wonder why we designed the system in such a way so as to have the reference of free pronouns in FID be fixed by an assignment different from the matrix assignment (in other words, Why have we "created" 'de dicto' pronouns?). And indeed, for cases such as (44b), a system that treats he as a 'de re' pronoun (whose value is fixed by the matrix assignment) would work just as well. The crucial job done by the embedded assignment becomes apparent when we look at those cases (discussed in section 3) where FID and SID contrast with each other with respect to the interpretation of free pronouns. We now look at these examples again. 


\subsection{Explaining FID/SID contrasts}

In the scenario where John stares at Bill and thinks that he is a woman (3.2), we noted a contrast between FID and SID with respect to the pronoun used to refer to Bill. The predicted interpretations are these (' $3 \mathrm{~F}$ ' stands for $3^{\text {rd }}$ person feminine).

John said that he looked great.

(cf. 17)

For all $\langle\mathrm{x}, \mathrm{t}, \mathrm{w}\rangle$ compatible with what John said in world(C), [I $h e_{3,4}{ }^{3 \mathrm{M}}$ past $_{2}{ }^{<}$look $-w_{1}$ great $\mathbb{I}^{\mathrm{c}, \mathrm{C}, \mathrm{g}[1 \rightarrow \mathrm{w}, 2 \rightarrow \mathrm{t}]}=1$.

She looked great(, he said). (cf. 16)

For all $\left\langle\mathrm{c}^{\prime}, \mathrm{g}^{\prime}\right\rangle$ such that c' is compatible with what John said in world(C)

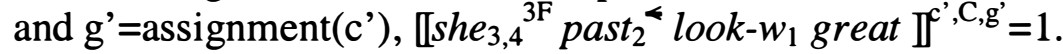

In the SID case, he is interpreted 'de re' (and refers to Bill - a male in the actual world), but in the FID case, we have to use she in order to convey John's point of view (and John thinks he is looking at a female).

Similarly, when a present tense is embedded under an attitude verb (in English), it is interpreted 'de re'. Not so in FID (see discussion in 3.3).

a. John found out that Mary is pregnant.

b. Mary is pregnant(, John is/\#was thinking).

We assume that the present tense carries a -PAST feature, and that it may lose this feature under agreement. We get (56) and (57) for (54a) and (54b) respectively.

(55) $\llbracket$ pres $_{\mathrm{i}, \mathrm{j}}{ }^{\mathrm{o}} \mathbb{I}^{\mathrm{c}, \mathrm{C}, \mathrm{g}}$ is defined only if $\mathrm{g}(\mathrm{j})$ overlaps $\mathrm{g}(\mathrm{i})$ and $\mathrm{g}(\mathrm{i})=$ time(c). When defined, $\llbracket$ pres $\mathrm{i}_{\mathrm{i}, \mathrm{j}}{ }^{\mathrm{d}} \mathrm{If}^{\mathrm{c}, \mathrm{C}, \mathrm{g}}=\mathrm{g}(\mathrm{j})$.

(56) For all $<\mathrm{x}, \mathrm{t}, \mathrm{w}>$ compatible with what John believed in world(C), II Mary pres $_{3,5}{ }^{\mathrm{o}}$ be pregnant $-w_{1} \prod^{\mathrm{c}, \mathrm{C}, \mathrm{g}[1 \rightarrow \mathrm{w}]}=1\left(\left[\text { pres }_{3,5}{ }^{\mathrm{o}}\right]^{\mathrm{C}, \mathrm{C}, \mathrm{g}[1 \rightarrow \mathrm{w}]}\right.$ overlaps time $\left.(\mathrm{C})\right)$

(57) For all $<c^{\prime}, g^{\prime}>$ s.t. c' is compatible with what John believes in C and g' =

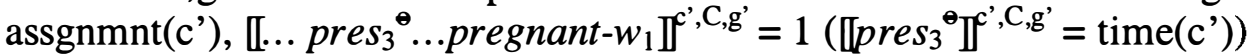

I do not know where the preference for a "null" present (rather than a 'de dicto' present, which would show itself in present-under-past FID; cf. (23a)) comes from, but the crucial point here is that the system correctly bans 'de re' present tense from FID (see Schlenker 2004 for a different view).

Regarding Condition B/C effects (3.4), the explanation for the contrast between (24) and (25) is based on the different points of view reflected by them.

(58) \#John muttered to himself that she didn't know her

(cf. 24)

For all $<\mathrm{x}, \mathrm{t}, \mathrm{w}\rangle$ compatible with what John said in world(C), [I not she $e_{4,5}{ }^{3 \mathrm{~F}}$ past $_{2}{ }^{4}$ know $-w_{1}$ her $_{4,7}{ }^{3 \mathrm{~F}} \mathbb{I}^{\mathrm{c}, \mathrm{C}, \mathrm{g}[1 \rightarrow \mathrm{w}, 2 \rightarrow \mathrm{t}]}=1$.

(59) She didn't know her(, he muttered to himself).

For all $\left\langle c^{\prime}, g^{\prime}\right\rangle$ such that c' is compatible with what John said in world(C) and g'=assignment(c'), [not she ${ }_{4,5}{ }^{3 \mathrm{~F}}$ past $_{2}{ }^{4}$ know- $_{1}$ her $_{4,7}{ }^{3 \mathrm{~F}} \prod^{\mathfrak{f}^{\prime}, \mathrm{C}, \mathrm{g}}=1$. 
In (58) $\mathrm{c}=\mathrm{C}$, and the pronouns are both 'de re' pronouns. Since we know John is looking at Mary, [she $\left.e_{4,5}{ }^{3 \mathrm{~F}}\right]^{\mathrm{c}, \mathrm{C}, \mathrm{g}}=\left[\text { her }_{4,7}{ }^{3 \mathrm{~F}}\right]^{\mathrm{c}, \mathrm{C}, \mathrm{g}}$ (=Mary). In (59), where the pronouns are interpreted 'de dicto', the values supplied by g' for these pronouns are different. In other words, [sh $e_{4,5}{ }^{3 \mathrm{~F}} \mathbb{I}^{\mathrm{c}}, \mathrm{C}, \mathrm{g}$ ' $\neq\left[\mathrm{Ther}_{4,7}{ }^{3 \mathrm{~F}} \mathrm{If}^{\mathrm{c}}, \mathrm{C}, \mathrm{g}\right.$ '.

Finally, consider again the antecedent options of it/that (section 3.5, (29)(30)). When he is interpreted 'de re' (in the SID case), we get a good result, because it refers to the proposition $<J o h n$, SICK $>$. But when he is interpreted 'de dicto', we get an odd result because it cannot refer to this proposition.

(60) John thought that he was sick. It wasn't true. John was perfectly fine.

$$
\llbracket \text { it/that } \rrbracket^{\mathrm{c}, \mathrm{C}, \mathrm{g}}=<\llbracket \text { he }_{6,3}{ }^{3 \mathrm{M}} \prod^{\mathrm{c}, \mathrm{C}, \mathrm{g}}(=\mathrm{John}), \mathrm{SICK}>
$$

(61) He was sick(, thought John). It wasn't true. \#John was perfectly fine.

$$
\llbracket \text { it/that } \rrbracket^{\mathrm{c}, \mathrm{C}, \mathrm{g}}=<\llbracket \text { he } e_{6,3}{ }^{3 \mathrm{M}} \mathbb{I}^{\mathfrak{c}^{\prime}, \mathrm{C}, \mathrm{g}^{\prime}}(\neq \mathrm{John}), \mathrm{SICK}>
$$

To sum up, the idea that the FID operator is a universal quantifier over context-assignment pairs, where 'context' is understood broadly, allows us to disallow 'de re' pronouns in FID. Recall, however, that $I$ is interpreted in FID as the author of the matrix context. This is explained in the following way. By adding an index to $I$ we make it a variable (cf. Heim 2001). By replacing the relevant part of (3b) with (62), we render it an inherently 'de re' pronoun.

For any index $\mathrm{j}$, $\left.\llbracket I_{\mathrm{j}}\right]^{\mathrm{C}}, \mathrm{C}, \mathrm{g}$ is defined only if assignment $(\mathrm{C})(\mathrm{j})=\operatorname{author}(\mathrm{C})$.

When defined, $\left.\left[I_{\mathrm{j}}\right]\right]^{\mathrm{c}, \mathrm{C}, \mathrm{g}}=\mathrm{g}(\mathrm{j})$.

The presuppositions in (62) and in (49)) together guarantee the right interpretation of $I$. Let us look at (1) (he would ask me $e_{3}$ to marry him) again. By the presupposition in $(62)$, assignment $(C)(3)$ is the speaker. The embedded assignment may assign the index 3 a different value (reflecting the fact that John might fail to recognize me). Still, the description that John uses to describe me to himself has to hold of me in the actual context as well (by (49)). You has a similar presupposition regarding the addressee.

\subsection{Can 'de dicto' pronouns account for 'de se'/'de nunc' readings in FID?}

There is a debate in the literature (Lewis 1979, Chierchia 1989, Reinhart 1991, Percus and Sauerland 2003, among others) concerning whether genuine "null" ('de se'/'de nunc') overt pronouns are really needed in the grammar of English. For example, it has been suggested that the 'de se' reading of Kaplan believes that his pants are on fire is a special case of the 'de re' reading, where he/his happens to refer to the attitude holder, and the attitude holder happens to know that he is the person he is in contact with. Therefore, only a 'de re' LF is needed.

A similar question arises for tenses. Given that tenses may be interpreted 'de re' (recall 'double access' readings), can a 'de re' interpretation of a past tense account for simultaneous 'de nunc' readings? Abusch (1997) shows that this is not always possible. Crucially, in the following example, the most deeply embedded past tense (under the most natural interpretation of the sentence) refers 
to a time of an event that occurs after the utterance time. A 'de re' interpretation of the past tense would require it to refer to a time before the utterance time.

A week ago, John decided that in ten days, during breakfast, he would tell his mother that he loved her.

This means that we need to assume a feature deletion mechanism (or some such mechanism, with the same effects) that allows the embedded tenses to be interpreted without their anteriority presuppositions.

\section{John past $_{4,5}{ }^{<}$decide 2 he past ${ }_{2}{ }^{\star}$ will tell his mother 3 he past ${ }_{3}{ }^{4}$ love her}

Since we have introduced 'de dicto' pronouns, it makes sense to ask, can we claim that 'de se'/'de nunc' readings of FID are always special cases of 'de dicto' readings? There are data that show that the answer is No. First, an example similar to (63) can be constructed using FID (cf. Kamp and Rohrer 1983).

Ten days from now, at breakfast, he would tell his mother that he loved her(, thought John a week ago).

The reading where the loving is simultaneous with the telling cannot be captured either by a 'de dicto' LF or by a 'de re' LF (which is excluded independently). As for person pronouns, notice that (66a,b) (based on Banfield 1982 and Doron 1991) contrast in acceptability when Mary mistakenly thinks she is a man.

(66) a. *He would make an excellent bishop(, thought Mary).

b. She would make an excellent bishop(, thought Mary).

(66a) is bad despite the fact that he is a male in the contexts compatible with what Mary believes (see (32b)). This is because, just like we normally don't use $3^{\text {rd }}$ person pronouns to talk or think about ourselves (whatever the reason for this might be), we normally cannot report someone else doing so. So the value of he is - in the normal case - distinct from the "embedded" author (Mary, or whoever Mary takes herself to be). (66b) is good because she is a 'de se' pronoun, whose gender features are deleted at LF under agreement with Mary. It is not a 'de re' pronoun because we have excluded 'de re' pronouns independently. It is not a 'de dicto' pronoun either, since we know from (16)-(17) that the gender features of 'de dicto' pronouns reflect the beliefs that the attitude holder has regarding the gender of the individual corresponding to it. (The reader is referred to Percus and Sauerland 2003 for an argument for genuine 'de se' pronouns based on SID.)

\section{Conclusion}

The behavior of pronouns in SID vs. FID suggests that the FID operator quantifies over broad contexts. On the other hand, the behavior of English attitude verbs is 
better understood if we don't regard them as quantifiers over broad contexts. It would be interesting to see, given this, how $3^{\text {rd }}$ person pronouns behave in languages where attitude verbs have been argued to be quantifiers over contexts on the basis of the shifted reference of various types of expressions in complement clauses of such verbs (Anand and Nevins 2004). If it turns out that these languages systematically ban 'de re' pronouns in the relevant cases, this might show that natural languages never use narrow contexts (and Schlenker's claim that all attitude verbs quantify over contexts might turn out to be incorrect).

\section{Endnotes}

*For very valuable comments, I thank the audience of SALT14, and the audiences who attended the talks I gave at MIT, UMass, Brown University, UConn, TelAviv University, The Hebrew University of Jerusalem, University of Tuebingen, and Tokyo University. Special thanks go to Philipppe Schlenker for our continuous and continuing discussions. All errors are of course mine.

${ }^{1}$ See Banfield (1982) regarding pragmatic restrictions on the use of $I / m e$ in FID.

2 Other time-adverbials that behave like this are this week, tomorrow, yesterday, etc. See Banfield and Doron for discussion of adverbs such as really (see also (16)), which are fine in FID but not in SID.

${ }^{3}$ In addition, for any root node $S$, no free and bound occurrences of the same index may occur in $S$.

${ }^{4}$ Judgments reported in Schlenker 2004 (which I do not share) conflict with these.

5 This doesn't explain why the pregnancy must also stretch into the past. See references cited for possible explanations of this fact.

${ }^{6}$ Schlenker (p.c.) points out correctly that present tense in FID is good in generic or characterizing sentences. For space limitations I do not go into this here.

${ }^{7}$ Also, the binder and the bindee must be interpreted relative to the same (big) $\mathrm{C}$.

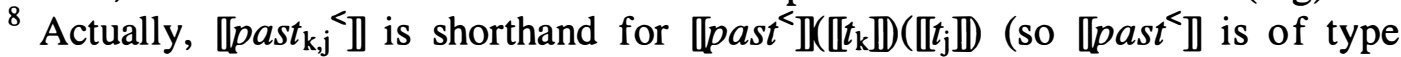

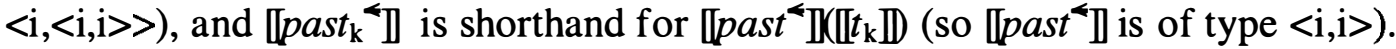
Similar comments apply to he.

${ }^{9}$ See Cresswell and von Stechow (1982), Heim (1994), and Percus and Sauerland (2003) a.o., for suggestions as to how this meaning is read off the syntax.

${ }^{10}$ Having an overt FID operator affords a simple account of SOT facts in FID. Notice that in non-SOT languages, the present serves as the "local" evaluation time in embedded clauses, in SID and FID (see Borer 1981, Sharvit 2003).

11 Paul Portner has pointed out to me that this semantics raises some issues regarding the introduction of new discourse referents in FID, and the use of pronouns to refer to them. I leave these problems open for now.

\section{References}

Abusch, Dorit (1997): 'Sequence of tense and temporal de re', Linguistics and Philosophy 20:1-50. 
Anand, Pranav and Andrew Nevins (2004): 'Shifty operators in changing contexts', Proceedings of SALT XIV, CLC Publications, Cornell Univ.

Banfield, Ann (1982): Unspeakable Sentences, Routledge \& Kegan Paul.

Borer, Hagit (1981): 'Heybetim leSoniyim Sel ha-maba ha-meSulav' (Linguistic aspects of the combined discourse). Hasifrut 30-31:35-57.

Chierchia, Gennaro (1989): 'Anaphora and attitudes de se', in R. Bartsch, J. van Benthem and P. van Emde Boas (eds.), Semantics and Contextual Expression, Foris, Dordrecht, 1-31.

Cresswell, Maxwell and Arnim von Stechow (1982): 'De re belief generalized, Linguistics and Philosophy 5: 503-535.

Doron, Edit (1991): 'Point of view as a factor of content', in S. Moore and A. Wyner (eds.), Proceedings of SALT 1, Cornell University, 51-64.

Heim, Irene (1994): 'Comments on Abusch's theory of tense', in H. Kamp (ed.), Ellipsis, Tense and Questions, DYANA deliverable R2.2.B, University of Amsterdam, 143-170.

Heim, Irene (2001): 'Semantics and morphology of person and logophoricity', manuscript.

Heim, Irene and Angelika Kratzer (1998): Semantics in Generative Grammar, Blackwell.

Kamp, Hans and Christian Rohrer (1983): 'Tense in texts', in R. Bäuerle, C.

Schwarze \& A. Von Stechow (eds.), Meaning, Use and Interpretation of Language, 250-269, de Gruyter, Berlin.

Kaplan, David (1979): On the logic of demonstratives. Journal of Philosophical Logic 8:81-98.

Kratzer, Angelika (1998). 'More structural analogies between pronouns and tenses', Proceedings of SALT VIII, CLC Publications, Cornell University.

Lewis, David (1979): 'Attitudes de dicto and de se', The Philosophical Review $88,513-543$.

Percus, Orin and Uli Sauerland (2003): 'On the LFs of attitude reports', in M. Weisgerber (ed.), Proceedings of Sinn und Bedeutung 7, 228-242. Universität Konstanz.

Quine, W.V.O. (1956): 'Quantifiers and propositional attitudes', the Journal of Philosophy 53, 177-187.

Reinhart, Tanya (1991): 'Self-representation', manuscript.

Schlenker, Philippe (1999): Propositional Attitudes and Indexicality, PhD dissertation, MIT.

Schlenker, Philippe (2003): A plea for monsters, Linguistics and Philosophy 26:29-120.

Schlenker, Philippe (2004): 'Context of thought and context of utterance (a note on Free Indirect Discourse and the Historical Present)', Mind and Language 19:279-304.

Sharvit, Yael (2003): 'Embedded tense and universal grammar', Linguistic Inquiry 34:669-681.

von Stechow, Arnim (2003): 'Feature deletion under semantic binding: tense, person, and mood under verbal quantifiers', text of the NELS33 talk. 